\title{
Evidence-Based Interventional Pain Medicine: Is There any Evidence?
}

\section{Laxmaiah Manchikanti, MD}

"True genius resides in the capacity for evaluation of uncertain and conflicting information."

- Winston Churchill

With this very practical and relevant quotation, the interventional pain medicine community, the insurance industry, epidemiological and scientific communities, and, finally, patients and government are challenged not only to formulate judgments but also to dissect through the present state of so-called evidence-based interventional pain medicine. Evidence-based interventional pain medicine is not a term that is officially used yet, but nevertheless is widely used with different meanings for different groups based on their vested interest.

Evidence-based medicine is a loose term which has been used based not only on the necessity to present a particular view, but also based on personal philosophy, bias and conjecture. Many have raised the question as to whether evidence-based medicine is really based on evidence. The second question is, does evidence-based medicine really work? The third question is, is there accountability? Finally, the fourth question is, is there lack of evidence or is it lack of ability to evaluate the evidence for what it is worth? Of course there are no answers for any of the questions. Evidence-based medicine has been proliferating ever since its inception. Some may say that evidence-based medicine is malignant. In the 1990s, numerous guidelines were published in various countries around the world; many professional organizations produced consensus guidelines, and the Cochrane Collaboration of systematic reviews, which started in 1992, now has more than 3000 collaborations worldwide. Today, evidencebased medicine is a fashionable term, which has been used to limit and deny medical care. Whereas it is science for some scientists, for others it is an entrepreneur's dreamland. In the field of pain,

From American Society of Interventional Pain Physicians. Dr. Manchikanti is the president and executive director of American Society of Interventional Pain Physicians. Address correspondence: Laxmaiah Manchikanti, MD, 2831 Lone Oak Road, Paducah, Kentucky 42003. E-mail: drm@asipp.org the first so-called evidence-based guidelines were produced by the Agency for Healthcare Policy Research (AHCPR) in 1994. AHCPR produced fifteen guidelines at a cost of $\$ 750$ million some costing more, some costing less. The Agency barely escaped total elimination, eventually surviving with only a small portion of its budget and then got out of the business of producing practice guidelines. What is now extremely important to be aware of is that even though these guidelines have been extinguished and do not represent current medical practice, so-called evidencebased proponents continue to use these guidelines, and base their analysis on them. To oppose this initial malignancy, congressional hearings were held and a book was produced (2). Multiple other books published subsequently on evidence-based pain medicine and others relevant to pain management include An Evidence-Based Resource for Pain

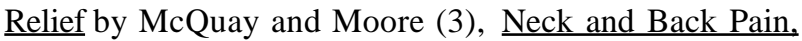
the Scientific Evidence of Causes, Diagnosis, and Treatment by Natchemson and Jonsson (4), Medical Management of Acute Lumbar Radicular Pain, An Evidence-Based Approach by Bogduk and Govind (5), Medical Management of Acute Cervical Radicular Pain, An Evidence-Based Approach by Bogduk (6) and, finally, User's Guide to the Medical Literature, A Manual for Evidence-Based Clinical Practice by Guyatt and Rennie (7). In addition, there has been a proliferation of literature not related to the spine and pain medicine. There have also been numerous guidelines and systematic reviews disguised as scientific publications and later claimed as evidence-based medicine based on the user's convenience.

\section{HISTORICAL CONSIDERATIONS}

Since Hippocrates, clinicians have been primarily interested in making accurate diagnoses and selecting optimal treatments for the patients in their practice. However, they must also avoid harmful exposures and offer patients prognostic information. Thus, evidence-based medicine, also known as EBM is about solving clinical problems (8).

To understand the prolific growth of evidence-based medicine, we have to look at the beginnings. During the late 1970s, a group of clinical epidemiologists at McMaster University, led by David Sackett, planned a series of ar- 
ticles advising clinicians on how to read clinical journals. This series appeared in the Canadian Medical Association journal beginning in 1981. The group proposed the term critical appraisal to describe the application of the basic rules of evidence presented in that series. These authors with their extensive experience of teaching critical appraisal for a number of years, became increasingly aware of both the necessity and challenges of motivating clinicians to go beyond merely browsing the literature and, rather, to actually use the information in solving patient problems. The term suggested by David Sackett was bringing critical appraisal to the bedside to describe the process of the practical application of evidence from the medical literature to the patient care. Thus, the concept of bringing critical appraisal to the bedside had evolved into a philosophy of medical practice based on knowledge and understanding of the medical literature supporting each clinical decision at McMaster University. It was believed that this represented a fundamentally different style of practice warranting a formal term that would capture the difference.

In 1990, Guyatt (7) suggested a new approach and coined the term scientific medicine. This bothered some implying that they were practicing unscientific medicine. Hence, the name was changed and, evidence-based medicine, was born. Thus, the term evidence-based medicine first appeared in 1990 in an informational document intended for residents entering or considering application to the residency program at McMaster University. The term subsequently appeared in print in the ACP journal club in 1991 (9). Innovators at McMaster University felt that because the process proved exciting and productive, they concluded that the concept of a new approach to medical practice would prove useful for the larger community of medical educators. Consequently, they linked up with a larger group of academic physicians, primarily from the United States, to form the first international evidence-based medicine working group, and published an article that expanded greatly on then existing description of evidence-based medicine, labeling it a paradigm shift (10). The Journal of the American Medical Association published a 25-part series called "The User's Guide to the Medical Literature" between 1993 and 2000, leading to the publication of a book (7). From evidence-based medicine, other terms have developed to fit the various needs of the healthcare profession including: evidence-based healthcare or evidencebased practice, and now, evidence-based interventional pain medicine.

Evidence-based medicine means many things to many people. It is similar to five blind men in a forest trying to assess what it is by touching an elephant. Five blind men who knew nothing about elephants went into the forest in search of one. The first to touch the elephant encountered the leg, and declared, "An elephant is like a tree." The next found the tail, and said, "You are wrong. An elephant is like a rope." The third reached the snout and affirmed, "You are both wrong. An elephant is like a snake." The fourth bumped into the side of the beast, and berating the others shouted, "You are all wrong. An elephant is like a wall." The fifth was brushed by the ear, and demanded, "What are you saying? An elephant is like a curtain."

Similar to that, Guyatt and Rennie (7) in their introduction section of the User's Guide to the Medical Literature, A Manual for Evidence-Based Clinical Practice, described a clinical scenario and discussed who is right about evidencebased medicine (7). The scenario was as follows:

A senior resident, a junior attending physician, a senior attending physician, and an emeritus professor were discussing evidence-based medicine over lunch in a hospital cafeteria. "EBM," announced the resident with some passion, "is a revolutionary development in medical practice." She went on to describe EBM's fundamental innovations in solving patient problems. "A compelling exposition," remarked the emeritus professor. "Wait a minute," the junior attending exclaimed with some heat, and then proceeded to present an alternative position: that EBM has merely provided a set of additional tools for traditional approaches to patient care. "You make a strong and convincing case," the emeritus professor commented. "Something's wrong here," the senior attending exclaimed to her older colleague, "their positions are diametrically opposed. They can't both be right." The emeritus professor looked thoughtfully at the puzzled doctor and, with the barest hint of a smile, replied, "Come to think of it, you're right too."

A current definition of evidence-based medicine is: the conscientious, explicit and judicious use of current best evidence in making decisions about the care of individual patients. Thus, evidence-based medicine is essentially what most clinicians have been trying to practice all their working lives. The practice of evidence-based medicine requires the integration of individual clinical expertise with the best available external clinical evidence from systematic research. Decisions that affect the care of patient should be made with due weight accorded to all valid, relevant 
information. There are many other factors in addition to the results of randomized, controlled trials, which may weigh heavily in both clinical and policy decisions, for example, patient preferences and resources, and these must contribute to decisions about the care of patients. Valid, relevant evidence should be considered alongside these other factors in the decision-making process. Thus, no one sort of evidence should necessarily be the determining factor in decision making. All implies that there should be an active search for all that is valid, relevant information and that an assessment should be made of the accuracy of information and the applicability of the evidence to the decision in question (3).

While numerous criteria have been established, all of them are similar and based on a vigorous analysis of the evidence. Finally, the evidence is analyzed based on each individual's philosophy. To analyze the evidence, one should be prolific, proficient, and persistent.

\section{EVIDENCE-BASED INTERVENTIONAL PAIN MEDICINE}

Some have disguised the reviews as systematic reviews and a necessary part of evidence-based guidelines but they are not intended as clinical guidelines (11). An evidencebased resource for pain relief edited by McQuay and Moore (3), a comprehensive text with analysis of many of techniques applied in the management of pain, has not been quoted in many of the so-called evidence-based guidelines or policies. There have been numerous systematic reviews, guidelines, policies, and practice parameters describing pain management, and in particular, interventional pain medicine (12-31).

Some of the reviews have drawn inaccurate conclusions based on an incomplete review of the literature, misunderstanding of the literature, and lack of representation from the interventional pain medicine community. We will review a few such instances.

Nelemans et al (22) reviewed multiple methods of treatment, reaching an inaccurate singular conclusion. They concluded that, "convincing evidence is lacking regarding the effects of injection therapy on low back pain." They vaguely described interventional techniques such aslocal injection therapy stating that local injection therapy is a badly defined term. It is well understood and well known that no one in interventional pain medicine uses the term local injection therapy. They also reported that there was no evidence for lumbar facet joint syndrome. However, a preponderance of evidence supports the existence of lumbar facet joint pain, with controlled studies describing variable prevalences from $15 \%$ to $52 \%$ based on type of the populations studied and the setting in which they were studied (32). Manchikanti et al (33) contended that the validity of facet joint injections has been strongly documented by properly designed studies as a gold standard in the diagnosis of facet joint pain. Nelemans et al (22) described only one study of facet joint injections which also used placebo injections which has been criticized extensively (34). Nelemans et al (22) also combined epidural injections with studies of disc injections, trigger point injections and facet joint injections. Thus, the review was totally flawed as the use of intradiscal injections, other than those for provocative discography, is not a common practice. In addition, they also combined all types of epidural injections, which are administered by multiple routes, which include caudal route, interlaminar route and transforaminal route. They failed to understand the significant differences in outcome among these techniques. The literature thus far has demonstrated that there is strong evidence for the efficacy of caudal injections and moderate evidence for transforaminal epidural injections when they are analyzed separately (12). Even further analysis of Nelemans et al (22) by Manchikanti et al (33) showed that four of the five studies involving caudal epidural steroid injections produced positive results, whereas five of seven studies on lumbar epidural steroid injections produced negative results. Of course, Nelemans et al's (22) review failed to review any transforaminal epidural injection studies.

The second review pertains to a systematic review of randomized clinical trials evaluating the efficacy of radiofrequency procedures for the treatment of spinal pain (23). This was another blow to interventional pain management. This review was similar to the review by Nelemans et al (22), as described above. Similar to Nelemans et al (22), Geurts et al (23) have mixed apples and oranges and also reached inaccurate conclusions. In addition, this was also followed by a glowing editorial by Carr (35). Guerts et al (23) reviewed six total studies, two of which were dorsal root ganglion radiofrequency studies, and a third study was intraarticular facet denervation. Therefore, out of six, only three studies were relevant. They also failed to include an excellent meticulously performed study by Dreyfuss et al (36) in the analysis and review, because this study had no control group. Thus, radiofrequency neurotomy of dorsal root ganglion is not a common procedure and has not been proven to be an effective modality for facet joint pain, whereas it is used, for segmentally radiating pain. Further, intraarticular 
radiofrequency, which is not an acceptable technique and has no physiologic or scientific basis for denervation as it should be performed on the medial branches or the dorsal ramus, rather than the joint itself was also included inaccurately in this review. Apart from all the confusion with regards to the identification of the best evidence hypothesis, three of the three studies were positive for radiofrequency management of facet joint pain with neurolysis. Thus, this should have yielded moderate to strong evidence rather than their strongest conclusion as Carr (35) noted, "insufficient evidence supporting the effectiveness of most radiofrequency treatments for spinal pain."

Natchemson and Jonsson's (4) evidence-based book also reached negative conclusions with diagnostic, as well as therapeutic interventional techniques, again due to lack of proper understanding and proper review of interventional techniques.

McQuay and Moore (3) extensively reviewed evidencebased resources for pain relief but this evidence has been ignored apparently because it does not fit the required criteria to deny medical care.

\section{RANDOMIZED TRIALS AND ECHELON JOURNALS}

Randomized, double-blinded studies are considered to represent the best available evidence. Thus, clinical efficacy of any intervention presumably is ideally measured by randomized, double-blind trials. Many stumbling blocks, including the issues of ethics, feasibility, cost and reliability, pose frequently insurmountable challenges to randomized, double-blind trials in interventional pain medicine (37-44). In addition, the value of the so-called "gold standard" of randomized, double-blind trials has been questioned. Benson and Hartz (45) outlined several advantages of observational studies over randomized, controlled trials including lower costs, greater timeliness, and a broader range of patients. They compared the results of observational studies with those of randomized, controlled trials. They concluded that in most cases, the estimates of the treatment effects from observational studies and randomized, controlled trials were similar. Concato et al (46) in evaluating various types of clinical evaluations concluded that average results of observational studies were remarkably similar to those of randomized, controlled trials and that the results of well-designed observational studies do not systematically overestimate the magnitude of the effects of treatment as compared with those in randomized, controlled trials on the same topic. Further, the statistical sig- nificance, which may not correlate with clinical significance (47) has been overemphasized in randomized clinical trials. Schulz et al (48) estimated that the lack of randomization may overestimate the treatment effect by $30 \%$ to $41 \%$; whereas the lack of blinding may overestimate the treatment effect by approximately $17 \%$, thus contributing to a maximum of $58 \%$ overestimation of the treatment effect. Thus, if one follows the dictum of randomized, controlled trials and uses the estimates of Schulz et al (48), a prospective evaluation but nonrandomized, non-doubleblind showing $80 \%$ effectiveness will actually be considered to be truly effective in only $22 \%$ of the patients due to the overestimation. Even though the publication of randomized, controlled trials concerning pain have increased significantly, only $14 \%$ of these studies investigated interventional techniques $(49,50)$.

Peer review also is highly variable. Webster's Dictionary defines peer as an equal in age, class, etc.; noble man. Thus, for interventional pain medicine, a reviewer should be considered a peer only if the reviewing person is a physician and practicing interventional pain medicine. Generally that is not the case. Most of the powerful journals are controlled either by their own healthcare professionals, such as chiropractors, physical therapists and psychologists, or specialists in medicine, including internal medicine, cardiology, anesthesiology, orthopedic surgery and spine professionals. Among the pain medicine specialists themselves, there are also behavioralists, interventionalists, and others who combine both approaches. Further differences among interventionalists include procedural specialists specifying their own interest and bias for one technique. Similarly, behavioralists also differ in their approaches, specifically regarding the administration of opioids. Essentially, as shown above, there is no true peer review available for interventional pain medicine except among a small handful of journals. To further complicate the picture, peer review is often made by academicians who may or may not practice interventional pain medicine but may be associated with one of the primary specialties. Lack of blinded review also affects peer review significantly. Thus, many of the studies performed by interventionalists per se, may not reach these major journals. Opposing views may not be published because they are considered too narrow and focused. Others are not published because of a lack of understanding of interventional pain medicine by the primary specialties.

Further issues have been raised regarding echelon journals. The questions is, "what is an echelon journal?" This is again a personal philosophy, bias, conjecture and poli- 
tics. Some consider the echelon journals to be the New England Journal of Medicine, the Journal of the American Medical Association, and the British Medical Journal. Any other journal, whether it is Anesthesiology, Spine, or the American Journal of Orthopedic Surgery are not considered to be echelon journals by these professionals. In contrast, some others consider their own journals as echelon journals and all others to be invalid and not credible. One should always ask these questions. Why would or should chiropractors consider medical journals as echelon? And vice versa? Why would specialists consider general medical journals echelon? Why would medical practitioners consider specialty journals echelon? Does one specialty journal consider another specialty echelon? And finally, how many journals focus on interventional pain management?

Lastly, a word about randomized controlled trials. Evidence based interventional pain medicine world embraced a randomized controlled trial published by Karppinen et al (51) on periradicular infiltration for sciatica, which was criticized as a less than optimal technique, reported in a study of 160 consecutive, eligible patients. They randomized the patients into two groups for double-blind injection with methylprednisolone, bupivacaine combination or saline. They reported better recovery in the steroid group at 2 weeks for leg pain, straight leg raising, lumbar flexion, and patient satisfaction. Back pain was significantly lower in the saline group at 3 and 6 months, and leg pain at 6 months. They also reported that by one year, 18 patients in the steroid group and 15 in the saline group underwent surgery. Thus, they reported that combination of methylprednisolone and bupivacaine provided only a short-term effect, if any. The results also reported that while patients were better at 2 weeks with methylprednisolone, they were better at 3 and 6 months with back and leg pain with saline group. This was a negative study. Paradoxically, Karppinen et al (52) also published another study using the very same patients, which evaluated the cost effectiveness of periradicular infiltration for sciatica. However, in this study, they divided the patients into subgroups with sciatica. The results showed in the case of the contained herniations, that steroid injection produced significant treatment effects and short-term efficacy in leg pain and health profile emotional reactions. They also reported that for symptomatic lesions at L3-L4-L5, steroid was superior to saline for leg pain, disability, and straight leg raising in the short term. They concluded that in addition to short-term effectiveness for contained herniations and lesions at L3L4-L5, steroid treatment also prevented surgery for contained herniations. These conclusions suggest a poor cor- relation between how these studies were conducted yielding such contradictory results, outcomes, and interpretations. No wonder there is confusion and we are left asking the question: "Is there any evidence for evidence - based interventional pain medicine?"

\section{CONCLUSION}

It appears that evidence-based interventional pain medicine has taken a wrong path and continues to travel down this path with lightening speed. Most of the reviews are performed by epidemiologists, or non-interventional pain physicians, or at times, non-healthcare professionals with no knowledge or practical knowledge and experience for understanding the intricacies of interventional pain medicine. Because of this, the efforts to provide a meaningful evidence-based interventional pain medicine reviews have been hampered. Thus, it is quite apparent that evidencebased interventional pain medicine neither meets the definition of David Sackett nor the philosophy of Archie Cochrane. To achieve the appropriate goals and to have real evidence-based interventional pain medicine and not to mix apples and oranges, the expert panels carrying out the systematic reviews and developing clinical or practice guidelines should include respected representatives of the interventional pain medicine community and avoid bias by following strict criteria when making comparisons among commonly used treatments.

\section{REFERENCES}

1. Bigos S, Bowyer O, Braen G et al. Acute low back problems in adults. Clinical Practice Guideline No. 14, AHCPR Publication No. 95 - 0642. Rockville, MD. Agency for Health Care Policy and Research, Public Health Service, US Department of Health and Human Services, December 1994.

2. Gonzalez EG, Materson RS (eds). The nonsurgical management of acute low back pain. Demos Vermande, New York, 1997.

3. McQuay H, Moore A (eds). An evidence-based resource for pain relief. Oxford University Press, New York, 1998.

4. Nachemson AL, Jonsson E (eds). Neck and backpain. The scientific evidence of causes, diagnosis, and treatment. Lippincott Williams \&Wilkins, Philadelphia, 2000.

5. Bogduk N, Govind J. Medical management of acute lumbar radicular pain. An evidence-based approach. Newcastle Bone and Joint Institute. Newcastle, 1999.

6. Bogduk N. Medical management of acute cervical radicular pain. An evidence-based approach. Newcastle Bone and Joint Institute University of 
Newcastle, Australia, 1999.

7. Guyatt G, Rennie (eds). User's Guides to the Medical Literature. A manual for evidence-based clinical practice. AMA Press, 2002.

8. Haynes RB, Sackett RB, Gray JMA et al. Transferring evidence from research into practice, 1: the role of clinical care research evidence in clinical decisions. ACP J Club, 1996; 125A:14-15.

9. Guyatt GH. Evidence-based medicine. ACP J Club 1991; 114:A-16.

10. Evidence-based medicine working group. Evidencebased medicine: a new approach to the teaching of medicine. JAMA 1992; 268:2420-2425.

11. van Tulder M, Malmivarira A, Esmail R et al. Letter to the editor: In reply. Spine 2001;26:840-844.

12. Manchikanti L, Singh V, Kloth D et al. Interventional techniques in the management of chronic pain: Part 2.0. Pain Physician 2001;4:24-96.

13. Spitzer WO, Leblanc FE, Dupuis M (eds). Quebec Task Force on Spinal Disorders. Scientific approach to the assessment and management of activity-related spinal disorders: A monograph for clinicians. Spine 1987; (suppl) 12:1-59.

14. Spitzer WO, Skovron ML, Salmi LR et al. Scientific monograph of the Quebec Task Force on whiplashassociated disorders: Redefining "whiplash" and its management. Spine 1995; (Suppl) 20:1-73.

15. Practice guidelines for chronic pain management. A report by the American Society of Anesthesiologists Task Force on Pain Management, Chronic Pain Section. Anesthesiology 1997; 86:995-1004.

16. Bogduk N. International Spinal Injection Society guidelines for the performance of spinal injection procedures. Part 1: Zygapophyseal joint blocks. Clin J Pain 1997; 13:285-302.

17. Campbell JK, Penzien DB, Wall EM. Evidence-based guidelines for migraine headache: Behavorial and physical treatments. 2000. Available at:

http://www.aan.com/public/practiceguidelines/ headache_gl.htm.

18. American Pain Society. Guideline for the management of acute and chronic pain in sickle-cell disease. American Pain Society, Glenview, 1999.

19. American Geriatrics Society. The management of chronic pain in older persons: New guidelines from the American Geriatrics Society. J Am Geriatr Soc 1998; 46:128-150.

20. Sanders SH, Rucker KS, Anderson KO et al. Clinical practice guidelines for chronic non-malignant pain syndrome patients. J Back Musc Rehabil1995;5:115120.

21. Sanders SH, Harden RN, Benson SE et al. Clinical practice guidelines for chronic non-malignant pain syndrome patients II: An evidence-based approach.J Back Musc Rehabil 1999; 13:47-58.

22. Nelemans PJ, Debie RA, DeVet HC et al. Injection therapy for subacute and chronic benign low back pain. Spine 2001; 26:501-515.

23. Geurts JW, van Wijk RM, Stolker RJ et al. Efficacy of radiofrequency procedures for the treatment of spinal pain: A systematic review of randomized clinical trials. Reg Anesth Pain Med2001;26:394-400.

24. Kepes ER, Duncalf D. Treatment of backache with spinal injections of local anesthetics, spinal and systemic steroids. Pain 1985; 22:33-47.

25. Benzon HT. Epidural steroid injections for low back pain and lumbosacral radiculography. Pain 1986; 24:277.

26. Bogduk N, Christophidis N, Cherry D et al. Epidural use of steroids in the management of back pain. Report of working party on epidural use of steroids in the management of back pain. National Health and Medical Research Council. Canberra, Commonwealth of Australia, 1994, pp 1-76.

27. Bogduk N. Epidural steroids for low back pain and sciatica. Pain Digest 1999; 9:226-227.

28. Koes BW, Scholten RJPM, Mens JMA et al. Efficacy of epidural steroid injections for low back pain and sciatica: A systematic review of randomized clinical trials. Pain 1995; 63:279-288.

29. Koes BW, Scholten R, Mens JMA et al. Epidural steroid injections for low back pain and sciatica. An updated systematic review of randomized clinical trials. Pain Digest 1999; 9:241-247.

30. Watts RW, Silagy CA. A meta-analysis on the efficacy of epidural corticosteroids in the treatment of sciatica. Anaesth Intens Care 1995; 23:564-569.

31. McQuay HJ, Moore RA. Epidural corticosteroids for sciatica. An Evidence-Based Resource for Pain Relief. Oxford University Press, Oxford, 1998; pp 216218.

32. Manchikanti L, Singh V. Review of chronic low back pain of facet joint origin. Pain Physician 2002; 5:83101.

33. Manchikanti L, Jasper J, Singh V. Cochrane review is mixing apples and oranges (ltr). Spine 2001; 26:26412643

34. Carrette S, Marcoux S, Truchon Ret al. A controlled trial of corticosteroid injections into facet joints for chronic low back pain. N Engl J Med 1991; 325:10021007.

35. Carr DB, Goudas LC. Evidence-based pain medicine: The good, the bad, and the ugly. RegAnesth Pain Med 2001; 26:389-393.

36. Dreyfuss P, Halbrook B, Pauza K et al. Efficacy and validity of radiofrequency neurotomy for chronic lumbar zygapophysial joint pain. Spine 2000; 25:12701277.

37. Hopwood MB, Manning DC. Lumbar epidural steroid injections: Is a clinical trial necessary or appropriate? Reg Anesth Pain Med 1999;24:5-7.

38. Turner JA, Loeser JD, Bell KG. Spinal cord 
stimulation for chronic low back pain. A systematic literature synthesis. Neurosurgery 1995;37:10881098.

39. Weinstein JN. The tortoise and the hare. Is there a place in spine surgery for randomized trials? Spine 1999; 23:2548-2549.

40. Winter RB. The prospective, randomized, controlled clinical trial in spine surgery. Fact or fiction? Spine 1999; 23:2550-2552.

41. Fairbank J. Randomized controlled trials in the surgical management of spinal problems. Spine 1999; 23:2556-2563.

42. Tosteson TD. Point of view. Spine 1999;24:25622563.

43. Carey TS. Randomized controlled trials in surgery. An essential component of scientific progress. Spine 1999; 23:2553-2555.

44. Turk DC, Okifuji A. Treatment of chronic pain patients. Clinical outcomes, cost-effectiveness, and costbenefits of multidisciplinary pain centers. Crit Rev Phys Rehabil Med 1998; 10:181-208.

45. Benson K, Hartz AJ. A comparison of observational studies and randomized, controlled trials. New EnglJ Med 2000; 342:1878-1886.
46. Concato J, Shah N, Horwitz RI. Randomized, controlled trials, observational studies, and the hierarchy of research designs. N Engl J Med 2000; 342:18871892.

47. Turk DC. Statistical significance and clinical significance are not synonyms! Clin J Pain 2000; 16:186187.

48. Schulz KF, Chalmers I, Hayes RJ et al. Empirical evidence of bias: Dimensions of methodological quality associated with estimates of treatment effects in controlled trials. JAMA 1995; 273:408-412.

49. Jadad AR, Carroll D, Moore A et al. Developing a database of published reports of randomized clinical trials in pain research. Pain 1996; 66:239-246.

50. McQuay H, Moore A. Finding all the relevant trials. An Evidence Based Resource for Pain Relief. Oxford University Press, Oxford, 1998, pp 5-9.

51. Karppinen J, Malmivaara A, Kurunlahti M et al. Periradicular infiltration for sciatica. A randomized controlled trial. Spine 2001;26:1059-1067.

52. Karppinen J, Ohinmaa A, Malmivaara A et al. Subgroup analysis of a randomized controlled trial. Cost effectiveness of periradicular infiltration for sciatica. Spine 2001; 26:2587-2595. 